\title{
Eco-epidemiological factors' of Head Lice in 10-12 year-old girls in Birjand City in 2017
}

Razieh Lashkari(M.Sc.) ${ }^{1}$,Mohammad Hassan Ehrampoush(Ph.D. $)^{2}$,GholamReza SHarifzadeh(M.Sc.) ${ }^{3}$, Mohammad Taghi Ghaneian (Ph.D.) ${ }^{4}$,Ali Dehghani (Ph.D.) ${ }^{5}$,Mohammad Ebrahimzadeh Ardakani (Ph.D.) ${ }^{6}$

1.M.Sc. Student of Human Ecology, Scool of Public Health, Shahid Sadoughi University of Medical Sciences, Yazd, Iran.

2.Corresponding Author: Professor, Department of Environmental Science and Technology Research Center, , School of Public Health, Shahid Sadoughi University of Medical Sciences, Yazd, Iran.

Email:ehrampoush@ssu.ac.ir Tel:09131518917

3.Assistant Professor, Department of Statistics and Epidemiology, School of Public Health, Birjand University of Medical Sciences,Birjand, Iran.

4.Professor, Research Center Environmental Science and Technology, Department of Human Ecology, School of Public Health, Shahid Sadoughi University of Medical Sciences, Yazd, Iran.

5.Assistant Professor, Department of Statistics and Epidemiology, School of Public Health, Shahid Sadoughi University of Medical Sciences, Yazd, Iran.

6.Assistant Professor, Department of Dermatology,School of Medical, Shahid Sadoughi University of Medical Sciences, Yazd, Iran.

Introduction: Lice are external parasites found in all socioeconomic classes around the world, which infect millions of people, especially children aged 5-14 years. Considering the growing and epidemiological trend of head lice in recent years, despite careful health care, more prognosis is needed. Therefore, this study aimed to study eco-epidemiological factors of head lice in 10-12 year-old girls in Birjand City in 2017.

Methods: This cross-sectional study with descriptive-analytic approach was conducted in Birjand City in the $201 \mathrm{v}$. The participants were selected using cluster sampling method from girl primary schools in Birjand City and its suburb areas. Data were entered into SPSS version 22 and analyzed by logistic regression test at significant level of 0.0 .5

Results: Head lice was evaluated in 2417 elementary school girls. The prevalence of head lice infection was $13.6 \%(n=329)$ in the population. The prevalence of contamination in urban areas was two times higher than the suburb areas. Significant correlations were observed between head lice infestation and father's education, mother's education, parent's job, family income, nationality, presence of foreigners in a class, habitat, history of previous student infections, presence of an infected person in the family, use of common Chador (piece of cloth worn by Muslim women to cover their body and hair) for praying at school. $(\mathrm{p}<0.05)$

Conclusion: The prevalence of head lice infection in the present study was higher than other studies. The prevalence of head lice infection was also higher in the suburbs. So, preventive measures, especially in the suburbs are required with regard to factors associated with infection by the health system.

Keywords: Ecological factors, Head lice, Girl, Primary school, Birjand

Conflict of interest: The authors declared that there is no Conflict interest

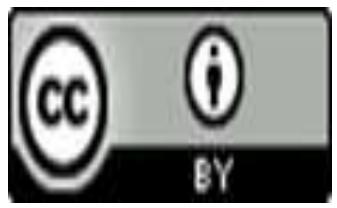

This Paper Should be Cited as:

Author:Razieh Lashkari,Mohammad Hassan Ehrampoush,Gholam Reza SHarifzadeh,Mohammad Taghi Ghaneian,Ali Dehghani,Mohammad Ebrahimzadeh Ardakani. Eco-epidemiological factors of Head Lice in 10-12 year-old girls in ..........Tolooebehdasht Journal.2020;19(1):84-99.[Persian] 


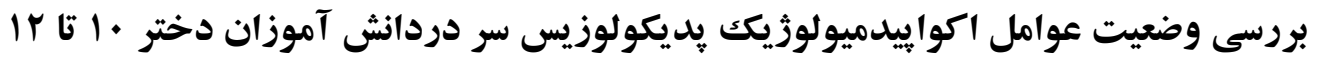

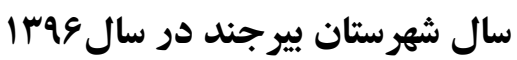

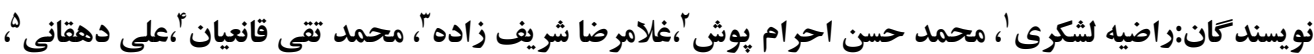

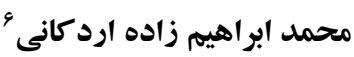
ا.دانشجوى كارشناسى ارشد اكولوزى انسانى، دانشكده بهداشت، دانشكاه علوم يز شكى و خدمات بهداشتى درمانى شهيد صدوقى ، يزد، ايران.

r.نويسنده مسئول :استاد مركز تحقيقات علوم و فناورى هاى محيط زيست، گروه مهندسى بهداشت محيط، دانشكده بهداشت،

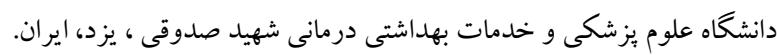
Email: ehrampoush@ssu.ac.ir

تلفن تماس:

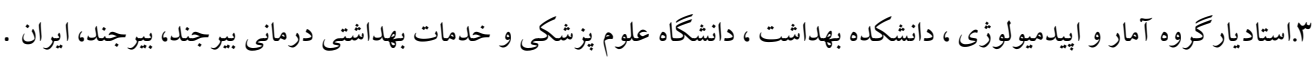

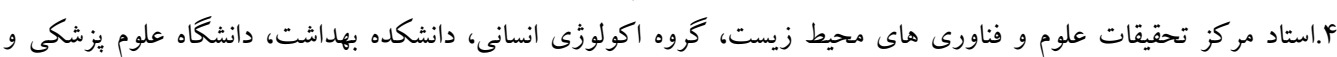
خدمات بهداشتى درمانى شهيد صدوقى، يزد، اير انسان.

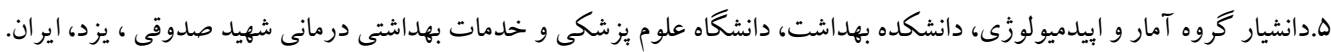

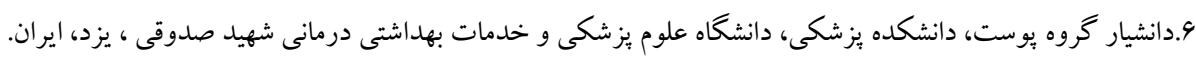

ention Egth

جكيده

مقدمه: شيشها انگل هاى خارجى با انتشار جهانى هستند كه در همه طبقات اجتماعى - اقتصادى در سراسر جهان

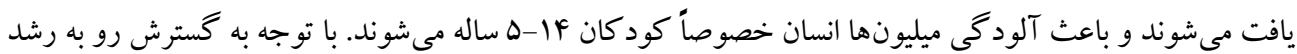
شيش سر در سالهاى اخير علىرغم مراقبتهاى بهداشتى دقيقتر،اين مطالعه باهدف بررسى وضعيت عوامل

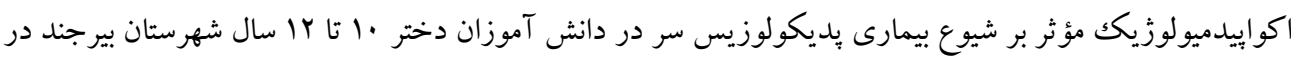
سال وه انجام گرديد. روش بررسى: اين يزوهش يكك مطالعه توصيفى - تحليلى است.جامعه آمارى دانش آموزان ابتدايى دبستانهاى

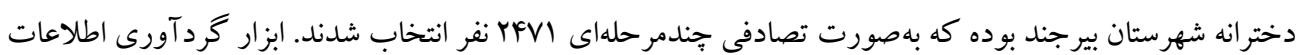

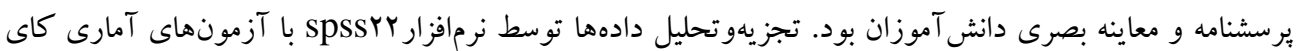

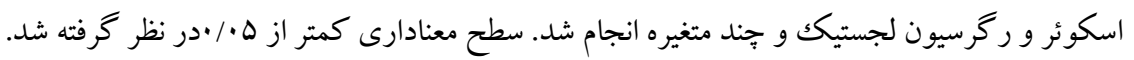

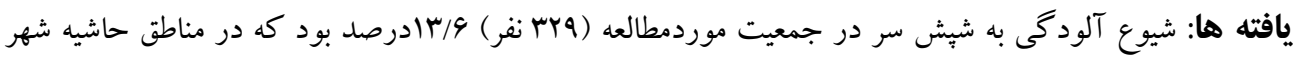

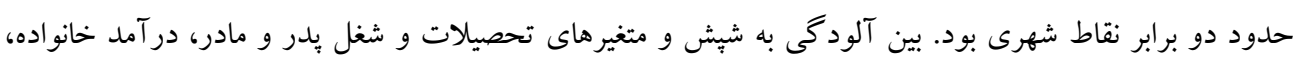

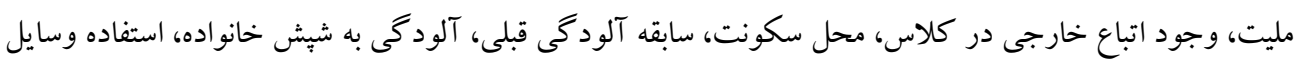

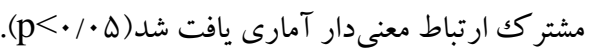

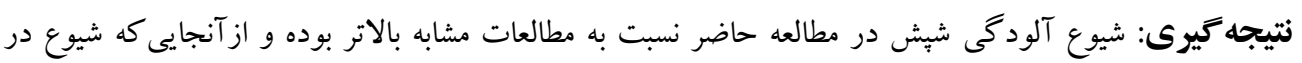

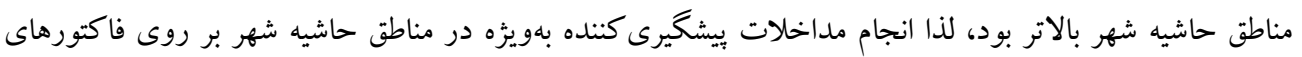

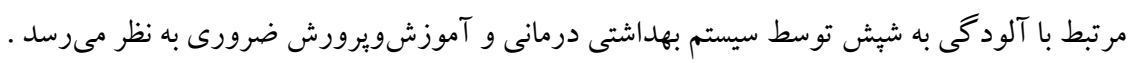
وازه هاى كليدى: عوامل اكولوزيك،، بديكولوزيس سر، دختر، مدارس ابتدايى، شهرستان بيرجند. اين مقاله حاصل بايان نامه كارشناسى ارشد كروه اكولوذّى انسانى ، دانشكده بهاشت دانشكاه علوم يزشكى شهيد صدوقى يزد مى باشد.

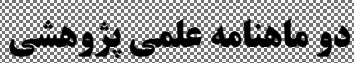

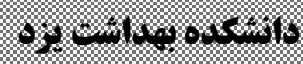
$\cos 30$ is J J Jol o low

Ir $14 \sin 20$

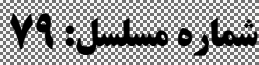

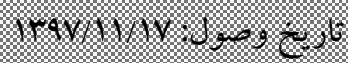

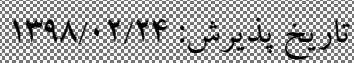




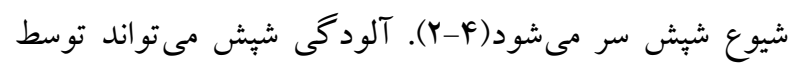
دانش آموزان از محيط مدرسه به خانواده منتقل شود(F).شيوع بديكولوزيس طى فصول مختلف سال متفاوت بوده و بيشترين

شيوع در تابستان و اوايل باييز مشاهدهده است(ه). مهمترين راه مبارزه با آلودگى شڤش استفاده از شاميوهاى محتوى حشرهشڤهاى جون ليندان، برمترين براى مبتلايان، آموزش همگانى و توانمندسازى افراد بهمنظور ارتقاء سطح بهداشت در جوامع هست(9) .در ايالاتمتحده آمريكا در بين ه درصد از كودكان سن مدرسه، ميزان بروز آلودگى بالا تهان گزارششده است (V). بر اساس انجمن بِديكولوزيس ملى آمريكا، ميزان آلودگى سر بيش از هـ درصد بهعنوان اندميك در

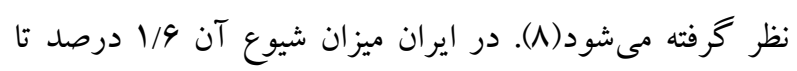
1r/4 درصد در تعدادى شهرها با زمينهاى اجتماعىدمو گرافى متفاوت گزارششده است(9). شيوع كل شِش سر در بين دانش آموزان مدارس ابتدايى ايران در يسران و دختران به ترتيب 9/ادرصد و/م/مدرصد بود(·().بر اساس نتايج مطالعات، شيوع آلودگى در استانهاى مختلف ايران مانند اروميه

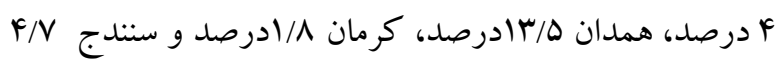
درصد مشاهده شده است (Y) ـ (1). بررسى هاى بهعمل آمده در كشورمان در خصوص بيمارى شبش سر، بيانخر شيوع آلودگى در ميان دانشآموزان است(11). با توجه به بررسىهاى بهمل آمده آخرين مطالعهاى كه در خصوص بررسى

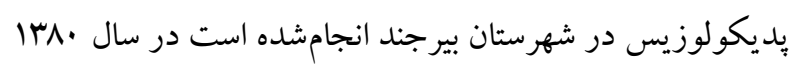
بوده است. در اين مطالعه شيوع بديكولوزيس بادرصد بود(I)).

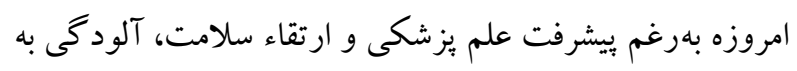
حشرات بهويزه انگل هاى خارجى همجنان سلامتى عمومى را
مقدمه اكولوزى انسانى بر مثلث بومشناسى انسانى، تأكيد دارد. اجزاى

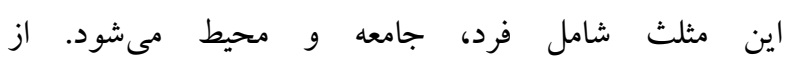
ديدگاه اكولوزى، بيمارى كاركرد نامناسب اندامهاى بدن در رابطه با محيطزيست است(1). بديكلوز سر، يكك انگل اجبارى خارجى و خونخوار بهاندازه Y-Fميلىمتر است كه روى يوست سر و موى انسان زندگى مى كند. تخمهاى شَش، يككشكل و بيضى مانند، سفيد و بهاندازه ته سنجاق است و به ساقه مو در

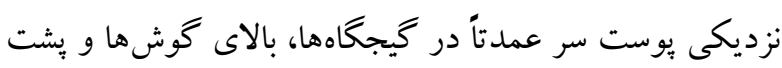
كردن مى جسبد و بهراحتى جدا نمى شود. براى تبديل يكك تخم به شڤي بالغ در شرايط مساعد سه هفته زمان لازم است. هر شَش سر در طول عمر فعال خود مجموعاً •ها-..1 تخم مى گذارد. بهطورمعمول تعداد شَش نزد افراد آلوده كمتر از ل1 عدد است، وقتى تعداد آنها كمتر از ه-ا عدد باشد ازنظر بالينى مشكل و عوارض عديدهاى ايجاد نمى كند. تخمهاى نزديكك بوست سر يا در فاصله r-r سانتىمترى زندهاند ولى آنهايى كه دورتر هستند، معمولاً خالى از جنين زنده بوده و نمى تواند عفونت را انتقال دهند(r،r). انتقال شيش سر از فردى رى به فرد ديخر از طريق تماس مستقيم در هنگام بازى يا تماس غيرمستقيم يعنى استفاده مشترك از وسايل نظير برس، شانه، لباس و حتى كمد لباس يا صندلىهاى عمومى، وسايل نقليه عمومى و كمدهاى لباس در استخرها، بهويزه در مكانهاى يرجمعيت مثل خوابكاهها، مدارس، مهلكودك و و زندان بهسرعت از فردى به فرد ديخر منتقل و منتشر مىشود. عواملى مانند وضعيت بهداشت نامناسب،وضعيت اجتماعى- اقتصادى پايين، مقاومت به حشره كشها و شكست درمان باعث افزايش 
اجتماعى و فرهنگى و زيرساخت شهرى شديداً دجار كمبود مى باشند، معمولاً قشر ساكن اين مناطق از لحاظ اقتصادى و سطح اجتماعى نسبت به ديخر مناطق شهر وضعيت ضعيف ترى

در منطقه شمال شهر rامدرسه دخترانه(با جمعيت VVVV انفر)، در منطقه جنوب شهر ·rمدرسه(با جمعيت ذهبrانفر) و در مناطق حاشيه شهر المدرسه(با جمعيت تعداد 19 اخوشه از مدارس انتخاب شد. به نسبت كل مدارس از منطقه شمال ه مدرسه، جنوب \ مدرسه و حاشيه شهر 9 مدرسه بهصورت تصادفى انتخاب و متناسب با جمعيت جامعه و حجم نمونه از هر بإيايه تحصيلى جهارم، بنجم و ششم نمونههاى موردنظر انتخاب گرديدند. حجم نمونه نيز بر اساس نتايج مطالعه جمع آور و همكارانش بر روى شيوع يديكولوزيس در دانش آموزان شهر بيرجند (كد طرح:QYV) و بر اساس فرمول

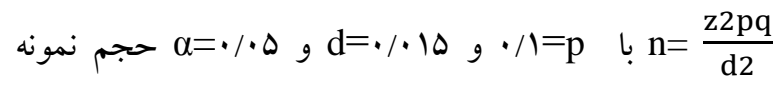
VrV خوشهاى با اعمال ضريب اصلاح روش نمونه گيرى خوشهاى ه/ابرابر حجم نمونه نهايى ه/بr/برآورد شده بود. روش انجام مطالعه ازاينقرار بود كه اطلاعات در دو مرحله يعنى مصاحبه و معاينه بهداشتى جمع آورى گرديد. شايان توجه است كه لوازم مورداستفاده در اين يزوهش،دستكش يككبارمصرف، آبسلانك و ذرهبين دستى بود. دادههاى مربوط به يُوهش از طريق ابزار يرسشنامه و معاينه موى سر ازنظر آلودگى به شيش جمع آورى ليش كرديد. از برسشنامه محقق ساخته حاوى وب سؤال كه شامل سؤالات دموكرافيك، إيدميولوزيك،، اكولوزيك بود جهت سنجش فاكتورهاى موثربر آلودگى شبش استفاده گرديد. ثبت
تهديد مى كنند. بـا توجهـ بـه تغييرات اكولوزيك و تأثير اين عوامل و هم جنين اثرات نامطلوب بهداشتى و روانى آلودكى شيش و لزوم كنترل بيمـارى و عدم انجام مطالعهاى در اين زمينه، اين مطالعه با هدف تعيين وضعيت عوامل اكواييدميولوزيكك مؤثر بر شيوع بيمارى بديكولوزيس سر در شهرستان بير جند انجام گرديد.

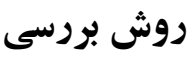

يُزوهش حاضر يك تحقيق توصيفى- تحليلى بود. جامعه موردمطالعه دختران دانش آموز · تا ب اسال ساكن در شهرستان بيرجند بودند كه به روش نمونه گيرى خوشهاى جندمرحلهاى تصادفى شده انتخاب گرديدند. حضور در جلسه مصاحبه، رضايت كامل والدين دانش آموزان در خصوص تكميل ير سشنامه و معاينه سر بهعنوان معيارهاى ورود و غيبت در جلسه مصاحبه و عدم رضايت جهت شركت در مطالعه از معيارهاى خروج از مطالعه بودند. ابزار مورداستفاده شامل يرسشنامهاى محقق ساخته مشتمل وَسؤال بود اين برسشنامه توسط • انفراز اساتيد مجرب، يكك متخصص عفونى و يك متخصص بوست در شهرستان بيرجند روايى آن بررسى شد. شهرستان بيرجند بر اساس شرايط جغرافيايى به مناطق شمال، جنوب و مناطق حاشيه شهر (امير آباد، حاجى آباد و جهكند) در سهبقه قرار گرفتند. براساس تعريف ستاد ملى باز آفرينى شهرى بايدار وزارت راه و

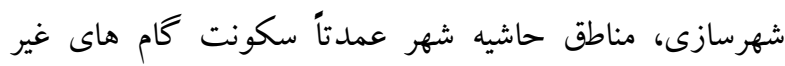
رسمى هستند كه بدون مجوز و خارج از برنامه ريزى رسمى و قانونى توسعه شهرى در درون يـا خـارج از محسدوده قانونى شهرها بوجود آمده اند، عمدتا فاقد سند مالكيت هستند و از نظر ويزگى هـاى كالبـدى و برخـوردارى از خـدمات رفـاهى، 
دولتى و سو نفر (Y/9 درصد)، در مدرسه غير دولتى تحصيل مى كردند. تعداد . مسY نفر (94درصد)، ايرانى و 9V نفر (F درصد)، مليت غير ايرانى (افغانى) داشتند . بيشترين تعداد دانش آموزان در گروه سنى 11 تا Y ا سال، درصد)، قرار داشتند. ..1 درصد دانش آموزان داراى مربى بهداشت بودند(جدول (). از نظر ميزان تحصيلات والدين، بيشترين تعداد . V نفر (q دوصد)، سواد متوسطه داشتند. بيشترين تعداد دانش آموزان شغل بدرشان ادارى VD Vفر (T/T درصد)، و مادران آنها خانه دار WMF انفر (V/9 درصد)، بود. هاه نفر( آ/ درصد)، از دانش آموزان از خادر نماز و جالباسى مشترك در مدرسه استفاده مى كردند(جدول Y). تعداد FY

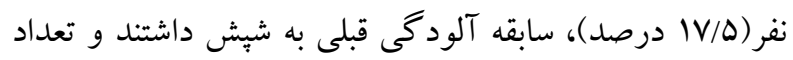

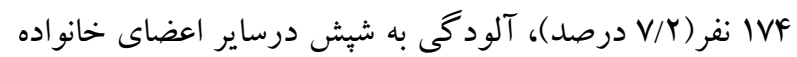

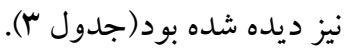
بر اساس يافتهاى بثوهش از ميان YFIV دانسش در آموز دختـر دبستانى ،وץ نفـــ (T/9/ درصد) آلوده به رشكك بودنـد. بـر ايسن اسـاس ميزان آلودگى در مدارس دولتى باو/بادرصد و در مقطع تحصيلى جهارم ابتدايى بـا 10/9 درصد و در بين دانش آموزان داراى مليت غير ايرانى /9·r درصد، بيشترين شيوع را

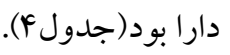

آلودگى به شبش در بين افراد ساكن مناطق حاشيه شهر (M/ه درصد)، افراد با تحصيلات بـدرومادر بـسواد (بـه ترتيـب بـه  درآمد خـانواده كمتر از ..مه هزار تومان (N/V درصد)، سابقه

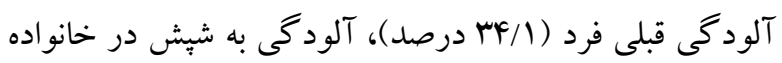
( F/A درصد)، نداشتن حمام در منزل(ها درصد)، بيشترين
اطلاعات در يرسشنامه توسط محقق و با كمكك مربيان بهداشت مدارس كه كارشناسان بهداشت بودند و از طريق مصاحبه مستقيم با دانش آموزان بهطور انفرادى انجام گرفت، سبس رتس معاينه مستقيم يوست و موى سر، موهاى يشت گُردن و اطراف كوش و يوشش سر دانش آموزان در حضور نور كافى و به مدت حدودع دقيقه توسط محقق انجام گرفت. تشخيص آلودگى بر اساس دستورالعمل استاندارد وزارت بهداشت صورت گرفت. مشاهده رشك يا شِش همراه با ضايعات بهصورت خراش جلدى با يا بدون عفونت در ناحيه پِت گوش و گردن به عنوان مورد قطعى ثبت گرديد. اطلاعات جمع آورىشده بهوسيله نرمافزار SPSS ورزن r ب ارزيابى شدند و با آزمونهاى كاى اسكوئر و رگرسيون لجستيك در سطح معنى دارى هـ/• تجزيه و تحليل شدند..شركت در اين يزوهش براى نوجوان دختر كاملاً داوطلبانه و حفظ حريم خصوصى وى است . با توجه به اينكه تعداد غايبين در جمعيت موردمطالعه خيلى كم بودند و در نتايج مطالعه تأثيرى نداشتند از بررسى آنها صرفنظر كرديد. اين طرح با كد اخلاق IR.SSU.SPH.REC.1396.147 در كميته اخلاق دانشكده بهداشت دانشكاه علوم بزشكى و خدمات بهداشتى درمانى شهيد صدوقى يزد مورد تصويب قرار گرفت.

\section{يافته ها}

بر اساس يافتهاى يُزوهش ميانگين سنى دانش آموزان شركت

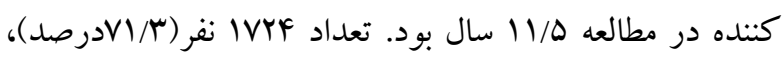
ساكن شهر و تعداد rو9 نفر (YN/V درصد)، ساكن مناطق حاشيه شهر كه MFV نفر ( MV/I درصد)، به خدمات بهداشتى اوليه دسترسى نيزداشتند . تعداد YYDF نفر (9V/F درصد) ، در مدارس 
افرادى كه بِرشان شاغل در بخش هاى دولتى(كارمند و نظامى) هستند كمتر از سايرين بود، شانس ابتلا با شغل بدر كاهشيافته

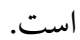

شانس ابتلا به آلودگى در افرادى كه شغل مادرشان خانهدار بود تقريباً ه/ ابرابر دانش آموزانى بود كه مادرشان شاغل در بيرون از

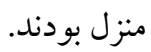
شانس ابتلا به شُش در افرادى كه سابقه آلودگى قبلى داشتند هابر افراد بدون سابقه قبلى است بين آلودگى به شبش و سابقه آلودگى قبلى دانشآموز رابطه معنىدارى وجود داشت. همجِنين شانس ابتلا به شتش در افرادى كه همزمان در خانواده آنها نيز آلودگى وجود داشت س/ها برابر دانش آموزانى بود كه در خانواده فرد آلوده نداشتند. شانس ابتلا به شيش در دانش آموزانى كه در مدرسه از جادرنماز مشترك استفاده مى كردند \&4/(برابر كسانى است كه از جادرنماز شخصى

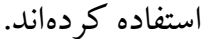

شيوع را به خود اختصـاص دادنــ. بِس از برازش مـدل ركرسيون لجستيك جند متغيره روى هر كدام از متغيرها، مشخص شد كه از بين كليه عوامل، محل سكونت و سابقه آلودگى قبلى فرد به شُش، بر ساير فاكتورها تاثيرداشت. بر آوردهـاى نسبت شـانس براى متغيرها در جدول عآمده است. مليت غير ايرانى تقريباً V/ابرابر ايرانىها شانس ابتلا به آلودحى را داشتند كه ازنظر آمارى نيز معنىدار شد. شانس ابتلا به شيش در دانش آموزانى كه در مناطق حاشيه شهر سكونت داشتند r/r/برابر بيشتر از دانشآموزانى بود كه در شهر زندكى مى كردند. دراينبين شـانس ابتلا به آلودگى در دانش آموزانى كـه تحصيلات بــدر و مادر آنها بىسواد يا ابتدايى بود بيشتر از كسانى بود كه تحصيلات والدينشان بالاتر از دييلم است.لذا

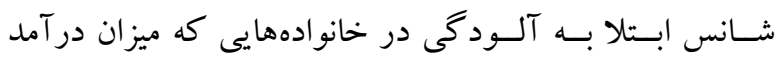
خانواده زير “له هزار تومان بود بيشتر است و با افزايش ميزان در آمد شانس ابتلا كاهش يافته است. شانس ابتلا به آلودگى در

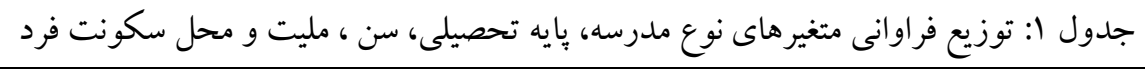

\begin{tabular}{|c|c|c|c|}
\hline درصد & فراوانى & & \\
\hline $9 V / F$ & YMDF & دولتى & نوع مدرسه \\
\hline$Y / 9$ & $9 \pi$ & غير دولتى & \\
\hline$r \Delta / \mu$ & NOr & پِيه جهارم & \\
\hline$r \mid r$ & vor & پِايه پِنجم & بايه تحصيلى \\
\hline$r \mu / 9$ & NIr & بايه ششم & \\
\hline$I V / r$ & fiv & • 1 سال & \\
\hline $94 / 1$ & lofq & 11 سال & سن \\
\hline IN/V & FOI & r آ سال & \\
\hline 99 & rMY. & ايرانى & مليت فرد \\
\hline f & qV & افاغنه & \\
\hline$v 1 / r$ & IVYF & شهر & محل سكونت فرد \\
\hline YN/V & 994 & حاشيه شهر & \\
\hline
\end{tabular}


q.

در مدل جند متغيره رگرسيون لجستيك، دو متغير محل سكونت و سابقه آلودگى قبلى فرد در پِايان در مدل باقى ماند. دانش آموزان حاشيه شهر شانس ابتلا هورك و قبلى آلودكى شانس \$ ه ابتلا برابرى نسبت به ساير افراد براى ابتلا به شيش
بهور كلى بين آلودگى به شبش و متغيرهاى مليت، محل سكونت، تحصيلات بِدر و مادر، شغل بدر و مادر، ميزان در آمد خانو اده، سابقه آلودگى قبلى فرد، وجود فرد آلوده در خانواده و استفاده از جادرنماز مشترك در مدرسه ازنظر آمارى رابطه

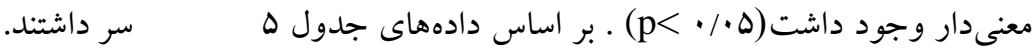

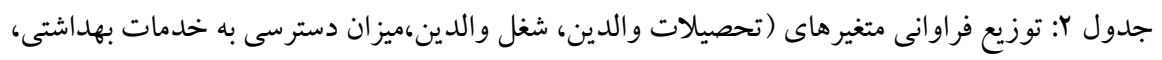

\begin{tabular}{|c|c|c|}
\hline درصد & فراوانى & \\
\hline$F / F$ & $1 \cdot v$ & بى سواد \\
\hline$r \cdot / 1$ & FAG & ابتدايى \\
\hline IV & 411 & راهنمايى \\
\hline$r q / 1$ & $V \cdot r$ & متوسطه \\
\hline$r N / r$ & 910 & دانشگاهى \\
\hline
\end{tabular}

$\Delta / 1 \quad$ IYF

rN/9

$11 / 0$

$r q / \Lambda$

$r / \mathrm{N}$

$\mu / r$

$r Y / 1$

$\Lambda / Y$

$\mid r / Y$

$11 / \%$

$1 \% / 9$

$V V / 9$

$9 / 9$

$10 / 1$

$9 \mathrm{~V} / 1$

$r / q$

$10 / 1$

$r r / 9$

YN/V

$\Delta 1 / \Gamma$
IYF

999

YA

vr.

$\Delta V F$

VQD

oro

191

raD

rVF

Toq

IMAF

$19 \mathrm{~V}$

r99

TMEV

v.

$r 90$

$\Delta V$.

IIV

IrF.
بىسواد

ابتدايى

راهنمايى

متوسطه

دانشخاهى

ادارى

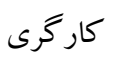

نظامى

كاسب و بازارى

آزاد

راننده و مشاغل مرتبط

خانهدار

شغل مادر

شاغل خانكى شانه

شاغل غير خانكى

ميز ان دسترسى به خدمات بهداشتى

ندارد

جادرنماز

استفاده از وسايل مشترك در مدرسه

جالباسى - (جاسن

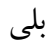

مسافرت والدين به كشو رهاى همسايه

خير 
91

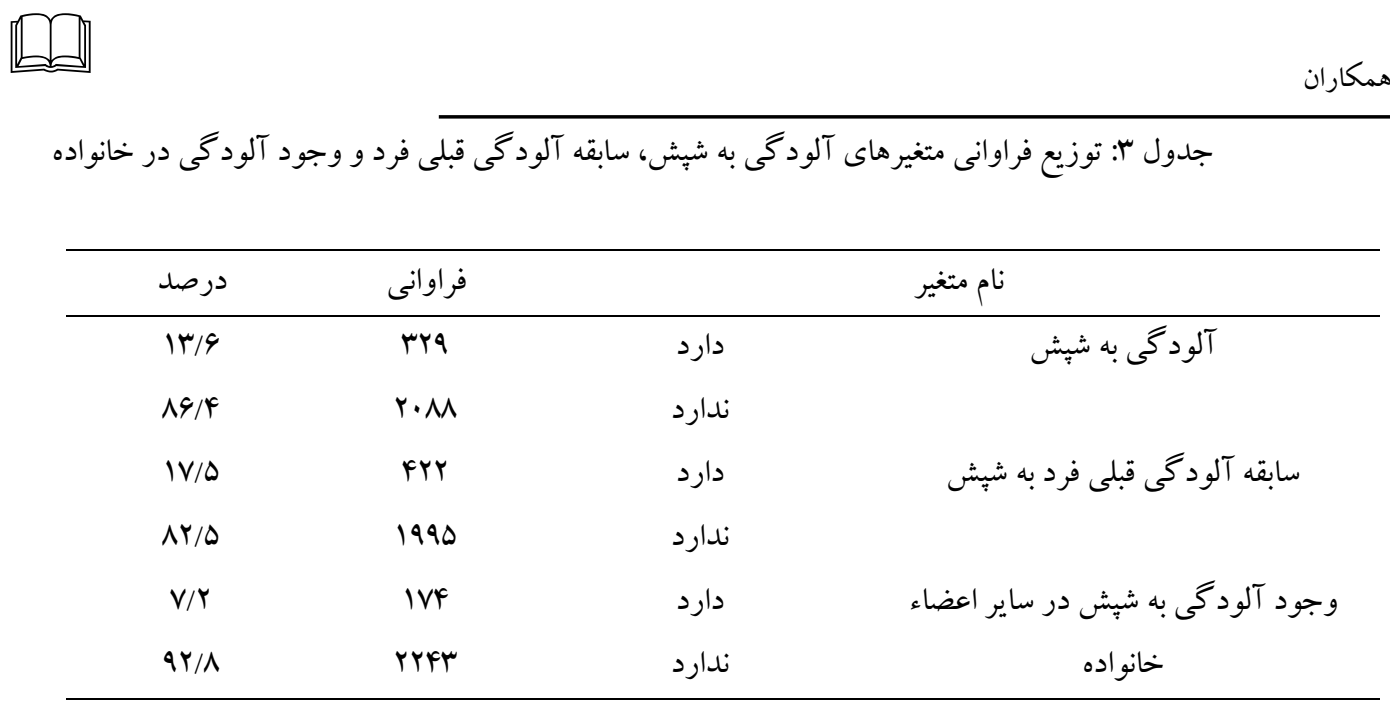

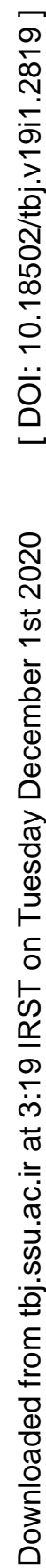

جدول f: فراوانى مطلق و نسبى متغيرهاى موردمطالعه و بر آورد نسبت شانس متغيرها

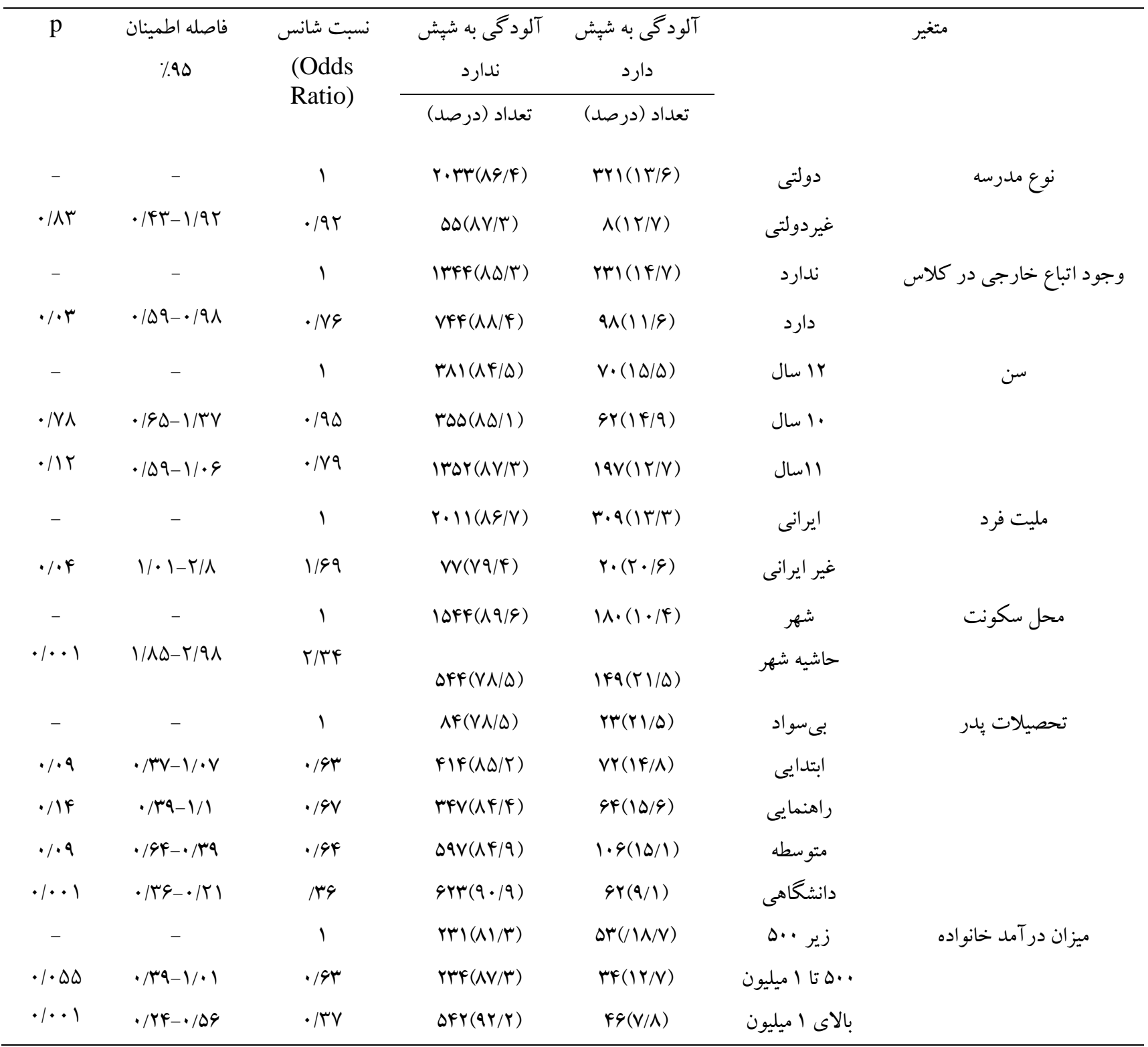


ar

[Dd

بررسى وضعيت عوامل اكوايدميولوزيكك بديكولوزيس سر دردانش آموزان دختر •ا تا با....

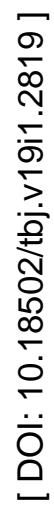

\begin{tabular}{|c|c|c|c|c|c|c|}
\hline- & - & 1 & $9 \vee(V \wedge / Y)$ & $Y V(Y \backslash / \Lambda)$ & بـ سواد & تحصيلات مادر \\
\hline .111 & $\cdot / 4 T-1 / \cdot 9$ & $\cdot \mid 9 \Lambda$ & $\Delta \wedge \vee(\Lambda F)$ & $11 Y(19)$ & ابتدايى & \\
\hline$\cdot|r|$ & $\cdot|4|-1 / 4$ & $\cdot|V|$ & $\operatorname{rMr}(\Lambda \Gamma / Q)$ & $F 9(19 / 0)$ & راهنمايى & \\
\hline$\cdot 1 \cdot .9$ & $\cdot|K|-\cdot \mid \lambda r$ & $\cdot|\Delta|$ & 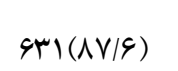 & $\Lambda 9(\mid Y / F)$ & متو سطه & \\
\hline$\cdot 1 \cdot \cdot 1$ & $\cdot|r|-\cdot|9|$ & 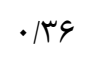 & rI $(9 \cdot \mid \Lambda)$ & $\Delta \Gamma(q / Y)$ & دانشگاهى & \\
\hline - & - & 1 & MIg(AN) & $\operatorname{Fr}(\mid r)$ & راننده و مشاغل & شغل بدر \\
\hline .111 & . $|\Delta|-1 / 11$ & $\cdot / V q$ & $9 \wedge 0(9 \cdot 19)$ & $V \backslash(9 / f)$ & ادارى & \\
\hline$\cdot 1 \cdot 1$ & $1 / \cdot 9-r / r q$ & $\mid / 91$ & $\operatorname{Rrq}(\Lambda r / 1)$ & $99(1 V / 9)$ & كارگرى & \\
\hline$\cdot 119$ & $\cdot / \Delta \varphi-1 / 9 \Delta$ &.$/ 9 V$ & $\operatorname{IV} \Delta(\Lambda \Lambda / \mathcal{F})$ & $r M(11 / 9)$ & 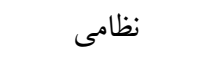 & \\
\hline .1 .9 & $\cdot / 9 Y-T / T V$ & $1 / 48$ & $\operatorname{rFG}(\Lambda T / Y)$ & $19(19 / 9)$ & كاسب و بازارى & \\
\hline .1 .9 & $\cdot / 9 V-r / r \Lambda$ & $1 / \Delta T$ & $\operatorname{rrV}(\Lambda \mathrm{r} / \Lambda)$ & $F V(I V / Y)$ & 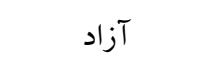 & \\
\hline- & - & 1 & $\operatorname{rY\Lambda }(\wedge 9 / \varphi)$ & $\mu \wedge(1 \cdot / \mathbb{f})$ & شاغل غير خانگى & شغل مادر \\
\hline$\cdot 1 \cdot \mathrm{f}^{\mathrm{c}}$ & $\mid / \cdot \wedge-r / \cdot G$ & $1 / F F$ & $191 f(\wedge \Delta / \mathrm{V})$ & $r V \cdot(I F / T)$ & خانهدار & \\
\hline$\cdot / 4 \Delta$ & $\cdot / V-T / 19$ & $1 / T F$ & $\operatorname{lf} q(\Lambda V / F)$ & $Y I(I T / 9)$ & شاغل خانكى & \\
\hline- & - & 1 & $1 \wedge 1 \cdot(9 \cdot / V)$ & $\wedge \Delta(9 / \Gamma)$ & خير & سابقه آلودگى قبلى فرد \\
\hline$\cdot 1 \cdot \cdots 1$ & $V / G-F$ & $\Delta / 1$ & $\operatorname{rVA}(\varphi \Delta / 9)$ & $\operatorname{IFF}(T K / \mid)$ & 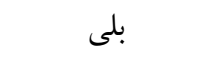 & \\
\hline- & - & 1 & $19 \wedge \Delta(\wedge \wedge / \Delta)$ & $r \Delta \wedge(1) / \Delta)$ & خير & وجود آلودگى در ساير افراد \\
\hline$\cdot 1 \cdot \cdot 1$ & $r / A r-V / r \Delta$ & $\Delta / r q$ & $1 \cdot r(\Delta 9 / T)$ & $V \mid(f \cdot \mid \Lambda)$ & 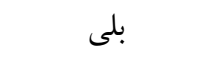 & خانو اده \\
\hline- & - & 1 & $\operatorname{IVQR}(\Lambda V / \mathcal{F})$ & $r \Delta Q(\mid r / q)$ & خير & استفاده از جادرنماز مشتر كى در \\
\hline$\cdot 1 \cdot \cdot 1$ & $1 / r Y-r / 19$ & l/94 & $r q \Delta(\Lambda \cdot / \Lambda)$ & $V \cdot(19 / T)$ & 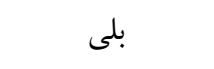 & 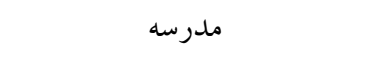 \\
\hline
\end{tabular}

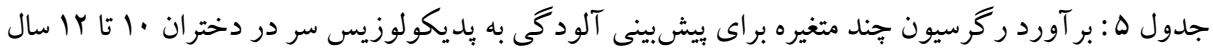

\begin{tabular}{|c|c|c|c|c|}
\hline \multirow[t]{3}{*}{$\mathrm{pv}$} & فاصله اطمينان هـ٪٪ & نسبت شانس & \multicolumn{2}{|c|}{ متغير } \\
\hline & & \multicolumn{3}{|l|}{ (Odds } \\
\hline & & \multicolumn{3}{|l|}{ Ratio) } \\
\hline \multirow[t]{2}{*}{$\mathrm{P}<\cdot / \cdot \cdot 1$} & - & 1 & شهر & \multirow[t]{2}{*}{ محل سكونت } \\
\hline & $1 / \Lambda r-V / 1$ & $r / \Delta q$ & حاشيه شهر & \\
\hline \multirow[t]{2}{*}{$\mathrm{P}<\cdot / \cdots 1$} & - & 1 & 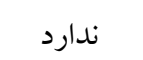 & سابقه آلود گى \\
\hline & $r / v q-11 / r$ & $\Delta / 9 \Delta$ & دارد & قبلى در فرد \\
\hline
\end{tabular}


همكاران در سالعArا ميزان آلودگى به شيش سر را در دانشآموزان دختر ابتدايى شهر قم ه/هادرصد گزارش

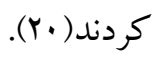

با توجه به استاندارد تعريفشده توسط انجمن علمى همكارى بين المللى در كنترل شُش سر، شيوع بالاى ه درصد را إيدمى تعريف مى كند(Y))، بر اين اساس شيوع شيش در مدارس ابتدايى دخترانه شهرستان بير جند در وضعيت إيدمى قرار داشت. كه نياز به آموزش خانوادهها، تمامى دانش آموزان(دانش آموزان مبتلا و سالم)و كاركنان مدارس، درزمينه شناسايى راههاى ييشخيرى، كنترل و گزارش موارد آلوده،بر گزارى جشنواره و مسابقات علمى آموزشى در رابطه با بيمارى بديكولوزيس و وتروتر ساير بيمارىها شديداً احساس مىشود. در قسمت ديخرى از يثزوهش بين آلودگى به شيش و وجود اتباع خارجى در

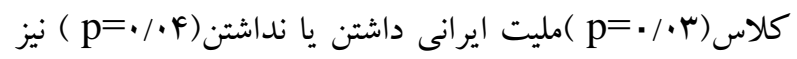
رابطه آمارى معنادارى مشاهده شد. اين موضوع در تحقيق بينشيان كه در سال هیr| در اردو گاههاى سمنان انجام شد نيز موردتوجه و تائيد قرارگر فته كه دليل بالا رفتن شيوع آلودگى به شيش سر را زندگى گروهى ذكر نموده است(Yr). واضح است كه معمولاً در جهان سوم مهاجران به كشورهاى همسايه به دلايلى مانند جنگك، نامنى، بيكارى، فقر و... مهاجرت مى كنند كه خود اين دلايل، باعث ايجاد يديده حاشيهنشينى در شهرها و مشكلات ناشى از آن ماند عدم دسترسى آسان به خدمات اوليه بهداشت عمومى، آب سالم، محل سكونت استاندارد و خيلى از موارد ديخر مىشود. بنابراين اين نقاط بهعنوان يكك نقطه برخطر و آلوده مىتواند نقش تأثير گذارى در انتقال، حفظ، رشد،
علىرغم يِشرفتهايى كه در جوامع مختلف ازنظر بهداشتى صورت گرفته است، آلودگى به شَش سر دركشورهاى درحال توسعه همجنان بهعنو ان يكى از معضلات بهداشتى مطرح است(rا). طبق مطالعات صورت گرفته در كشور ايران آلودگى به شَّ سـر در نقاط مختلف كشور وجود دارد و بر اسـاس آمسارWHO ايران ازجمله مناطق آلوده به اين بيمـارى در جهان است(1). شيوع بديكولوزيس دركشورهاى مختلف دنيا، تا.A

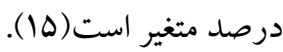
شيوع آن در جهان از اواسط دهه .99 افزايشيافته، بهطورى كه در مطالعات إيدميولوزيك در مدارس كشورهاى مختلف شيوع "يديكولوزيس در فرانسه هادرصد، كره استراليا V/ ليبى NV/9 درصد، لبنان ^ درصد، اسرائيل ههدرصد و در انكلستان//N/ درصد بود(1)). بر اساس دادههاى بهدست آمده از يُزوهش حاضر ميزان آلودگى به شيش سر در بين دانش آموزان

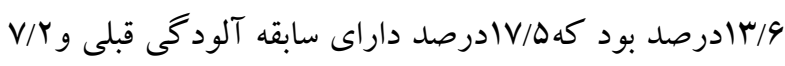
درصد خانواده آنها نيز آلودگى به شيش داشتند. در مطالعه نوروزى و همكاران در سال1\%A9 كه به بررسى شيوع شيش سر و عوامل موثربر آن در دانشآموزان ابتدايى دخترانه مناطق روستايى قم برداختند نيز ميزان آلودگى شيش سر س/rادرصد كزارش شد(IV) كه با يافتهاى مطالعه حاضر هم خوانى داشت. همجنين عيوضى در مطالعه شيوع شبش سر در مدارس ابتدايى

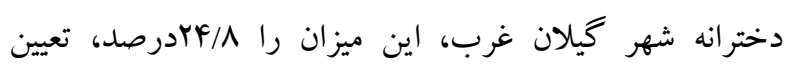
كرد(1) كه ميزان شيوع آن نسبت به يافتهاى مطالعه حاضر

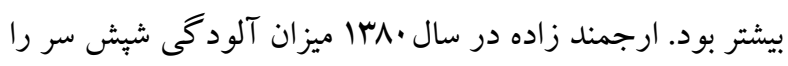


معنى راههاى انتقال را مانند انتقال از طريق مدارس، اجتماعات عمومى مانند سرويس مدارس و...يررنغكتر جلوه دهد. متولى حقى و همكارانش، رفيعى و همكاران در سالهشזاو كاكتورك (Tس، TY (T) در يافتهاى مطالعه خود بين شيوع بديكولوزيس و تحصيلات بِدر دانش آموزان ارتباط معنادارى را ززارش دادند در مطالعه حاضر نيز بين آلودگى به شيش و تحصيلات بالاتر

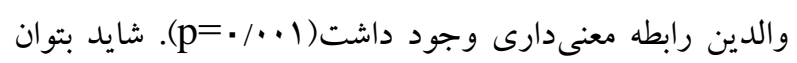
كفت كه افزايش سطح سواد والدين مىتواند به نسبت سطح كيفيت زندگى، تربيت فرزندان، آموزش روش زندگى بهداشتى و فردى فرزندان و آكاهى فرزندان را جهت رفع مشكلات و يا حتى جلو گيرى از بروز آن به همراه داشته باشد. شانس ابتلا به

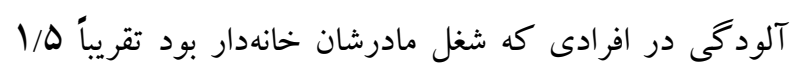
برابر دانش آموزانى بود كه مادرشان شاغل در بيرون از منزل بودند، بين آلودگى به شتش و شغل مادر ارتباط معنىدارى

$$
\text { وجود داشت( }
$$

همجينين شانس ابتلا به آلودگى در افرادى كه بِدرشان شاغل در بخشهاى دولتى(كارمند و نظامى) هستند كمتر از ساير يدران است، شانس ابتلا با كارمند بودن كاهش يافته است. بين آلودگى بـ

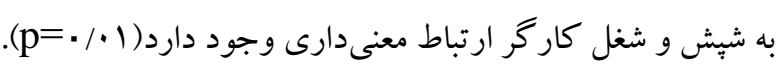
درو گر و همكاران بين ميزان آلودگى به شتش سر و شغل بدر رابطه معنىدارى را گزارش نمودند(ها) در مطالعه مشابه انجامشده در سنندج بدران كارمند فرزندان آلوده كمترى داشتند(Y) كه نتايج هر دو مطالعه با يافتهاى مطالعه حاضر همسو بود. درحالى كه بيات و همكاران در سالي ته I در استان همدان بين آلودگى دانش آموزان و شغل بدرانشان ازنظر آمارى
شدت، و بروز ساير بيمارىها باشد. بين آلودگى به شپش و متغيرهاى دولتى يا غيردولتى بودن مدرسه (r/A=/p)، تراكم دانش آموزان در كلاس(p=|p) مدرسه ( / . (p=) رابطه معنى دارى مشاهده نشد كه با نتايج مطالعه نوروزى و همكاران هم خوانى داشت. شايد بتوان كفت كه تفاوت طبقه اجتماعى والدين و همان اندازه ميزان سواد سلامت آنها بر اين فاكتور مىتواند تا اندازه قابلتوجهى تأثير گذار باشد. شانس ابتلا به شيش در دانش آموزانى كه در مناطق حاشيه شهر سكونت داشتند ب/T برابر بيشتر نسبت به دانش آموزانى كه در شهر زندگى مى كردند بود، بين آلودگى به شڤش و محل

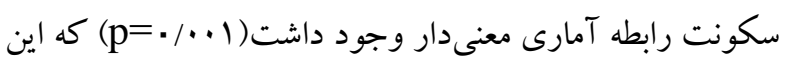
يافته نيز با نتايج مطالعه قادرى در سال•^شا و همكاران

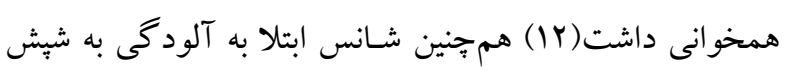
در دانش آموزانى كه به خدمات بهداشتى دسترسى نداشتند 9.1/ برابر بيشتر از دانش آموزانى بود كه به خدمات بهداشتى دسترسى داشتند ولى ازنظر آمارى معنى دار نشد(19/ - p=). نوروزى و همكاران، نكويى نائينى و مصطفوى بين وضعيت دسترسى به خدمات بهداشتى درمانى و آلود گحى به شپش سر در

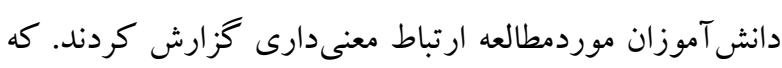
با يافتهاى اين يثوهش در تضاد بود(IV). يرواضح است كه هرجه ميزان دسترسى و قابليت استفاده از سيستم بهداشتى درمانى و خدمات اوليه سلامت بيشتر باشد به همان اندازه نيز سطح سواد سلامت و بالطبع رفتارهاى بهداشت فردى و اجتماعى نيز قوىتر و دقيقتر اجرا خواهد شد. مشابه با

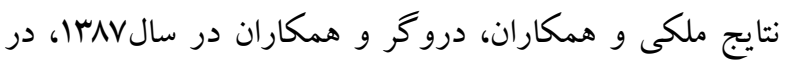
مطالعه حاضر نيز بين آلودگى به شبش و بعد خانوار رابطه آمارى 
شانس ابتلا به شُش در افرادى كه در منزل به حمام دسترسى نداشتندץ// برابر بيشتر از دانش آموزانى است كه دسترسى به حمام داشتند. بين آلودگى به شبش و داشتن حمام در منزل رابطه معنى دارى وجود نداشت(p=/p). همجنين شانس ابتلا به آلودگى در دانشآموزانى كه هر دو هفته يككبار استحمام مى كردند ^•/(برابر از كسانى بود كه يككبار در هفته استحمام مى كردند ولى ازنظر آمارى بين آلودگى به شبش و تعداد

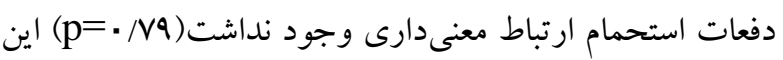
در حالى بود كه نوروزى و همكاران در يزوهش خود در سال هAM ارتباط معنىدارى بين دفعات استحمام با ميزان شيوع آلود گى مشاهده كردند بهطورى كه هرجه وضعيت بهداشتى فرد بهتر باشد، آلودگى كمتر خواهد بود، لذا استحمام مرتب مى تواند باعث عدم ابتلا و حتى كاهش آلودگى شود؛ كثيرى، رفيع نزاد و همكاران در سال هیז|، مطلبى و مينويان حقيقى در مطالعات خود نيز به نتايج مثبت استحمام مرتب در كاهش آلودگى اشاره نمودهاند(IV)كه با يافتهاى يُزوهش حاضر همسو نبود. هم جنين بين آلودگى به شيش و استفاده از جالباسى مشترك در مدرسه از نظر آمارى رابطه معنىدار وجود

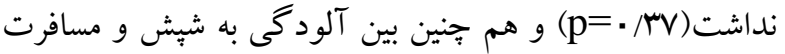
والدين به كشورهاى همسايه(ب/ه=-p) و نخهدارى حيوان در منزل ازنظر آمارى رابطه معنى دار وجود نداشت(pV)./PV). از طرفى بين آلودگى به شيش و استفاده از جادر نماز مشترك

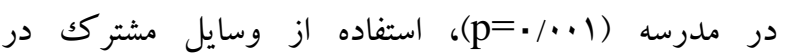

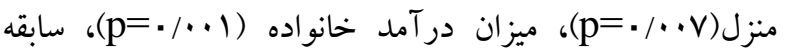
آلودگى قبلى دانشآموز(1)

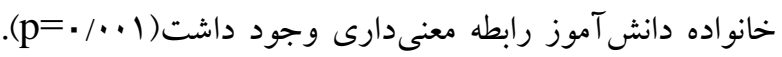

رابطه معنى دارى را ززارش نكردند(YV). نوروزى و همكاران نيز در مطالعه خود ارتباط معنىدارى بين ميزان آلودگى و سطح تحصيلات و شغل والدين گزارش نكردند كه با نتايج مطالعه حاضر همسو نبود. نوروزى و همكاران دليل عدم ارتباط سطح تحصيلات والدين و آلودگى به بديكولوزيس را دلايلى ماند مشغله كارى و يا تحصيلات غير مرتبط با دانش بهداشت و يشخگيرى و كنترل بيمارى والدين عنوان داشتند(IV). در اين بين شـانس ابتلا به آلودگى به شڤش در بين گروه سنى rاسال ، بيشتر از ساير گروههاى سنى است. دانشآموزان بايه تحصيلى

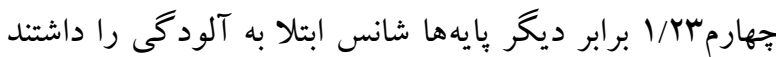
ولى ازنظر آمارى معنىدار نشد(ب/ / = (p). در مطالعه دروگر و همكاران در سال •وسا كه به بررسى ميزان عوامل موثربر آلودگى به شڤش سر در دانش آموزان مدارس ابتدايى شهر آران بيدگل يرداختند توزيع فراوانى آلودگى در دانش آموزان سوم ابتدايى مبتلابه شيش سر بيشتر از ساير بِيههاى تحصيلى بود. آزمون آمارى بين ابتلا به شڤش سر و بايههاى مختلف تحصيلى و افزايش سن رابطه معنادارى نشان نداد كه اين بخش از يافتها بامطالعه حاضر همسو بود(YN). همجِنين در مطالعه ذبيحى و همكارانش نيز آلودگى به شيش سر در سنين مختلف تفاوت حندانى نداشته است و ارتباط معنادارى بين شيوع يديكولوزيس و سن دانشآموزان مشاهده نشد. از طرفى بر اساس مطالعات مشابه انجامشده درصد شيوع آلودگى به شيش سر در سنين بالاتر از9 سال كمتر از ساير سنين بوده است(19) شايد بتوان وابستخى بيشتر كود كان كم سن به مادران و اطر افيان جهت انجام بعضى از مسائل بهداشتى مانند حمام كردن و شانه زدن موهاى سر را يكى از دلايل توجيه اين يافتها دانست. 
با توجه به اينكه فرد آلوده مى تواند آلودگى را به خانواده انتقال نمايد، آموزش به دانش آموزان و والدين در خصوص راههاى انتقال بيمارى، استفاده از وسايل شخصى، آكاهى والدين از روش هاى درمان و مراقبت هاى لازم(كو تاه كردن موى دختران، استفاده دقيق از شاميو در زمان بيمارى، معاينه مرتب موهاى سر دانش آموز، مراجعه به نزديك ترين مركز خدمات جامع سلامت جهت دريافت شاميو در صورت نياز) مىتواند در كنترل بيمارى ر ر ر بسيار مؤثر باشد. ارائه اقدامات و مداخلات بيشكيرى كننده توسط سازمان آموزشويرورش شامل: بهكارگيرى مربيان بهداشتى متخصص و مجرب بهخصوص در مدارس ابتدايى، بركزارى كلاسهاى آموزشى براى مديران و معلمان، كاهش تعداد دانشآموزان در كلاسهاى درس، حذف جالباسى و جادر نماز مشترك در مدارس، انجام معاينات هفتگى دانشآموزان توسط مربى بهداشت و ويخيرى موارد آلوده تا درمان، كامهاى بسيار مؤثرى در حذف اين بيمارى خواهد بود. توجه بيشتر دولتمردان به مناطق حاشيه شهرها و اختصاص امكانات بهداشتى به اين مناطق نيز از ديخر اقدامات مؤثر در

$$
\text { كنترل بيمارى است. }
$$

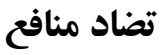

نويسند كان اين مقاله اعلام مى دارند كه هيج گونه تضاد منافعى

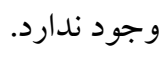

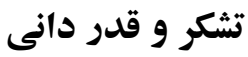

بدينوسيله از زحمات مديران و مربيان بهداشت، كار كنان مراكز خدمات جامع سلامت شهرستان بيرجند كه ما را در انجام اين يُّوهش يارى نموده اند تشكر و قدردانى مى گردد .
داورى و همكاران(YN) نيز در سال دو متغير آلودگى به شتش و سابقه ابتلا قبلى را مشاهده كردند. كه با يافتهاى حاضر همخوانى داشت، درواقع همه اين فاكتورها به گونهاى به شرايط بد بهداشتى، عدم مصرف صحيح داروها، مقاومت انكل، بيدايش نمونهاى انخلى مقاوم به درمان، طبقه اجتماعى، ميزان اطلاعات بهداشتى، سطح معيشتى خانواده و...بستخى دارد. در بايان با توجه به يافتهاى متفاوتى كه از يُزوهش هاى مختلف حاصل شده شايد بتوان دلايل مختلفى را در رابطه با اين اختلافات بيان نمود، درواقع در مطالعات توصيفى متغير زمان و مكان فاكتور تأثير گذار و مهمى است لذا با گذر زمان و از طرفى تأثير ساير فاكتورهاى اجتماعى بر جامعه و مردم همجون ميزان تورم، ايجاد فاصله طبقاتى، خشكسالىهاى يىدريى و به دنبال آن ايجاد محدوديتهاى مالى، بيكارى و بهداشتى ماند كمبود آب، كمبود آب سالم بهداشتى، كوج كردن از نواحى روستايى و منازل با متراز بالا، به مناطق حاشيه شهرها كه بهطور مستقيم فاكتورهايى مانند استاندارهاى بهداشتى محل سكونت، فرهنگ اجتماعى محل سكونت، بهداشت فردى، ميزان سواد سلامت در آن نواحى بايين تر از حد استاندارد است، دلايل قابل توجيهى براى بيان اين اختلاف آمارى است. همجنين از متغيرهايى مانند ابزار مورداستفاده در يُزوهشها، متد و روش مطالعات، جامعه آمارى موردمطالعه، ناحيه جغر افيايى و وضعيت آب و هوايى منطقه موردمطالعه نيز نبايد غافل شد. به نظر يكى از بهترين راهكارها جهت رفع ابهامات موجود بررسى يكك مطالعه ميدانى در سطح ملى و بررسى مطالعات متعدد در هر منطقه جهت تأيد و قوت گرفتن نتايج مطالعات ساير يزوهشخران در همان منطقه است. 


\section{References}

1- Moshki M, Zamani-Alavijeh F, Mojadam M. Efficacy of peer education for adopting preventive behaviors against head lice infestation in female elementary school students: a randomised controlled trial. PloS one. 2017;12(1):e0169361.

2-Jarahi Lida OR, Elaheh Vahed Seyedeh, Mosa.Farkhani Ehsan. Assessment of Demographic Caracteractists and Related Factor on Head Lice in Mashhad, a population based. Medical Journal of Mashhad University of Medical Sciences. 2017;59(6):305-11.[Persian]

3-Barbara L,Frankowski, MD, Leonard B. Weiner, MD. Head Lice. Guidance for the Clinician in Rendering Pediatric Care. 2002;110(3):638-43.

4-Kamiabi F, Nakhaei FH. Prevalence of pediculosis capitis and determination of risk factors in primary-school children in Kerman. EMHJ - Eastern Mediterranean Health Journal. 2005;11(56):988-92(persian) https//:apps.who.int/iris/handle/10665/117030.

5-Bauer E, Jahnke C, Feldmeier H. Seasonal fluctuations of head lice infestation in Germany. Parasitology research. 2009;104(3):677-81.

6-Rafinejad J, Nourollahi A, Biglarian A, Javadian E, Kazemnejad A, Doosti S .The comparison of the effect of permethrin shampoo and lindane lotion on the treatment of head lice (Pediculus Humanus Capitis) in the primary school pupils. Journal of Mazandaran University of Medical Sciences. 2011;21(83):35-41.[Persian]

7-Abd El Raheem TA, El Sherbiny NA, Elgameel A, El-Sayed GA, Moustafa N, Shahen S. Epidemiological comparative study of pediculosis capitis among primary school children in Fayoum and Minofiya governorates, Egypt. Journal of community health. 2015;40(2):222-6.

8-Ismail MT, Kabakibi MM, Al-Kafri A. Epidemiology of pediculosis capitis among schoolchildren in Damascus, Syria. Indian Journal of Paediatric Dermatology. 2018;19(4):331.[Persian]

9- Mehr Aghaei. M. Prevalence of head lice infestation and its effective factors in elementary school students in Ahvaz city in winter 2016 and spring 2017. Ahwaz University of Medical Sciences. 2016;101.[persian]

10- Moosazadeh M, Afshari M, Keianian H, Nezammahalleh A, Enayati AA. Prevalence of Head Lice Infestation and Its Associated Factors among Primary School Students in Iran: A Systematic Review and Meta-analysis. Osong Public Health and Research Perspectives.2015;6(6):34656.[Persian] 
11- Saghafipour A, Akbari A, Norouzi M, Khajat P. The epidemiology of pediculus is humanus capitis infestation and effective factors in elementary schools of Qom Province Girls 2010, Qom, Iran. Majallah-i Dānishgah-i Ulum-i Pizishki-i Qum. 2012;6(3):46-51.[Persian]

12- Ghaderi R, Eizadpanah AM, Miri MR, Ahmadi M, Taheri N, Hoseinzadeh Chahkandak F. The Prevalence of pediculosis capitis in school students in Birjand. Modern Care Journal (Scientific Quarterly of Birjand Nursing \& Midwifery Faculty). 2010;7(1):49-54.[Persian]

13-Motevali hagh F RnJ, Hoseeni M. Prevalence pediculosis and associated risk factors in primaryschool children of Mazandaran Province, Iran, 2012-2013. J Mazand Univ Med Sci. 2014;23(110):82-91.[Persian]

14-Morovati Sharif Abadi M, Moghadasi Amiri M, Falah Mehrjordi S, Aghaei A, Zareshahi F, Alizadeh S. Pediculosis Capitis and Its Related Factors among Girl Primary School Students of Meybod, Yazd Province, in 2015-2016. Journal of Health. 2018;8(5):552-60.[Persian]

15- Bharija SC KA, Singh G, Belhaj MS. Pediculosis capitis in Benghazi, Libya. A school survey. . Int JDermatol.1988;27(3)165-166.

16- Zabihi Ali JAr, Rezvani Mohsen, bichani Ali. Evaluation of head lice infestation rate in primary school students in Babol city in 2004-2005. Journal of Babol University of Medical Sciences. 2006;7(4):88-93.[Persian]

17-Noroozi M, Saghafipour A, Akbari A, Khajat P, Khadem Maboodi AA. The prevalence of pediculosis capitis and its associated risk factors in primary schools of girls in rural district. Journal of Shahrekord Uuniversity of Medical Sciences. 2013;15(2):43-52.[Persian]

18-Aivazi.A.Epidemiology of Pediculus humanus capitis infestation and effective factors in elementary schools of children, Islam Abad city, Kermanshah province.Tehran:Tarbiat Modarres University. 1986.[Persian]

19-Arjmandzahe. The survey of prevalence of Pediculus humanus capitis infestation and Scabies in elementary schools of children, Boushehr city. Iran South Med J. 2001;4(1):41-6.[Persian]

20- Farzinnia B HBA, Reis Karami S, Jafari T. Epidemiology of Pediculosis capitis in female primary school pupils Qom. Hormozgan Med J. 2004; 8(2):103.[Persian]

21-MorowatiSharifabad M.A EM, Fazeli F, Dehghani A, Neshati T. Study of Pediculus capitis prevalence in primary school children and its preventive behaviors determinants based on Health Belief Model in Their Mothers in Hashtgerd, 2012. Journal of Toloo-e-behdasht. 2016;14(6):200-9. 
22-Bineshian F. Evaluation of superficial and cutaneous fungal diseases among Afghan immigrants in Semnan refuge camp. Semnan University of Medical Sciences. 2010;68(1):45-53.[Persian] 23-Rafiey A KH, Mohammadi Z, Haghighizadeh MH. The Factors that may be influencing the prevalence of head lice in primary school girl children Ahvaz city. Journal of infectious diseases. 2008;4(45):41-5.[Persian]

24-KOkturk A bk, bugdayci R. The prepalence of pediculosiscapitis in school children in Mersin, turkey. Int J Dermatol. 2003;42(9):694-8.

25- Doroodgar A, Sadr F, Paksa A, Mahbobe S, Doroodgar M, Sayyah M, et al. The prevalence of pediculosis capitis and relevant factors in primary school students of Kashan, Central Iran. Asian Pac J Trop Dis. 2014;4(6):500-4.[Persian]

26-Pour Baba R MHM, Habibi Pour R, Mirza Nezhad M. . A survey of prevalence of Pediculosis among primary school students of Guilan province in the school year of 2002-03. Journal of Medical Faculty Guilann University of Medical Sciences. 2005;13(15-23).[Persian]

27- Bayat S HPR. prevalence of head lice and head fungal infections in primary school students in the Hamadan province 2004-2005. Articles abstract book of sixth national conference and the first regional congress of parasitology and parasitic diseases, Research Institute Vaccine and Serum making of Razi,Karaj. 2008. [Persian]

28- Davari B KM, Poormohammdi, Faramarzi Gohar A, Faizei F, Rafat Bakhash S, Ahmadi S. An Epidemiological study of Pediculus capitis in students of Pakdasht county, in autumn of 2013. Pajouhan Scientific Journal. 2013;14(1):57-63.[Persian] 